\title{
Outcome following single intravitreal injection of ranibizumab in branch retinal vein occlusion patients: a single centre experience
}

\author{
Meherda A. ${ }^{1}$, Parida S. ${ }^{2}$, Choudhury D. ${ }^{3}$, Dash N. ${ }^{4}$, MehfuzAlam A. ${ }^{5}$ \\ ${ }^{1}$ Dr. Ashwani Meherda, Senior Eye Specialist, Capital Hospital, Bhubaneswar, ${ }^{2}$ Dr. Subhabrata Parida, Professor, ${ }^{3}$ Dr \\ Deepak Choudhury, Senior Resident, ${ }^{4}$ Dr. Nikita Dash, $3^{\text {rd }}$ Year Resident, ${ }^{5}$ Mr. Akbar MehfuzAlam, Sightsaver, \\ 2,3,4,5 authors are affiliated with Regional Institute of Ophthalmology, SCB Medical College, Cuttack, Odisha, India.
}

Corresponding Author: Prof Dr. Subhabrata Parida, Regional Institute of Ophthalmology, SCB Medical College, Cuttack, Odisha, India. E-mail-drsidharth74@gmail.com

\begin{abstract}
Objective: To find out outcome following single intravitreal injection of ranibizumab in branch retinal vein occlusion (BRVO) patients in a government hospital in the capital of Odisha. Methods: This study was a prospective interventional study of 18 months duration, done from August 2017 to February 2019 which included 21 cases of BRVO. Thorough history was taken and detail ophthalmological evaluation was done. Best corrected visual acuity (BCVA) was examined with Snellen's chart and central macular thickness (CMT) was measured using optical coherence tomography (OCT). Routine blood tests were done. Intravitreal injection of ranibizumab $0.5 \mathrm{mg}$ in $0.05 \mathrm{ml}$ was given. BCVA and CMT was measured at 1 day, 1 week, 1 month and 3 months follow up visit. Results: Mean age was $55.29 \pm 16.86$ yrs. Male: female ratio was $3.2: 1.33$. About $3 \%$ patients presented within 1 month of onset of symptoms. Diastolic blood pressure of $\geq 90$ was found in $81 \%$ patients. $90.5 \%$ showed improvement at 1 week post-operatively.At post-operative day $1 \mathrm{CMT}$ was significantly decreased $(\mathrm{p}=0.0011)$. Reduction in mean CMT at post-operative day 7 was $>270 \mu$. Conclusion: Single intravitreal injection of ranibizumab $0.5 \mathrm{mg}$ in 0.05 mlcauses significant increase in vision and significant reduction of central macular thickness in patients with branch retinal vein occlusion.
\end{abstract}

Keyword: BRVO, Ranibizumab, Optical coherence tomography (OCT)

\section{Introduction}

Occlusion of the retinal venous system is more common than arterial occlusions. Retinal vein occlusion (RVO) is a major cause of vision loss. Of the two main types of RVO, branch retinal vein occlusion (BRVO) is 4 to 6 times more prevalent than central retinal vein occlusion (CRVO) [1].

Systemic hypertension along with thrombus formation is the most likely cause of occlusion. Compression of vein by extraluminal factors and inflammation of the vessel wall are other causes.Branch retinal vein occlusion (BRVO), the second most common vascular disorder of the retina, typically occurs at arteriovenous $(\mathrm{A} / \mathrm{V})$ crossings where the arteriole and venule share a common adventitial sheath. Mechanical narrowing of the venous lumen at these intersections is thought to play a pathoetiologic role in BRVO [2].

Manuscript received: $21^{\text {st }}$ March 2019

Reviewed: $1^{\text {st }}$ April 2019

Author Corrected: $5^{\text {th }}$ April 2019

Accepted for Publication: 11 ${ }^{\text {th }}$ April 2019
An increased risk of branch retinal vein occlusion was found in persons with a history of systemic hypertension, a history of cardiovascular disease, an increased body mass index at 20 years of age, a history of glaucoma, and higher serum levels of $\alpha_{2}$-globulin [3].

Etiological factors include ocular factors and systemic factors. Ocular risk factors include glaucoma, trauma, retinal vasculitis, central retinal artery occlusion, arterio-venous malformation. Systemic factors include cardiovascular risk factors like atherosclerotic heart disease, diabetes mellitus, hyperlipidemia, obesity, smoking, rheological abnormalities like increased haematocrit, increased plasma viscosity, increased red cell aggregation, thrombophilia due to hyperhomocysteinemia, anti-phospholipid syndrome, oral contraceptives, hyperviscosity syndromes like polycythemia, myeloma, leukemia. Patients with retinal venous occlusive disease have higher levels of homocysteine, which may serve as a modifiable risk factor [4]. 


\section{Original Research Article}

Venous occlusion may be detected incidentally during routine eye check-up. Patients may present with sudden, rapid loss of vision if macular haemorrhage or vitreous haemorrhage is present. Gradual loss of vision is present in cases of macular edema, macular ischemia, tractional detachment of macula. In branch retinal vein occlusion (BRVO), dilatation and tortuosity of the veins and intra-retinalhemorrhages in corresponding quadrant is present.Elevated intraocular levels of vascular endothelial growth factor (VEGF) have been found in patients with retinal venous occlusion [5]. Sustained intravitreal release of VEGF in primate eyes causes widespread retinal vascular leakage, breakdown of blood retinal barrier and macular edema. So anti-VEGF may be used in BRVO with macular edema. Ranibizumab is a humanized, VEGF antibody fragment that neutralizes all isoforms of VEGF-A. Intravitreal injection of ranibizumab $0.5 \mathrm{mg}$ may be given in BRVO [5]. If macular edema is the cause of fall of visual acuity of less than 6/12, macular grid photocoagulation may be undertaken. If macular non-perfusion is the cause of decreased vision, no laser treatment is performed. In this study the effects of single dose intravitreal injection of ranibizumab $0.5 \mathrm{mg}$ in $0.05 \mathrm{ml}$ in BRVO patients were evaluated.

\section{Methods}

Study Design- This study was a prospective interventional study of 18 months duration done from August 2017 to February 2019 in a government run hospitalof Odishawhich included 21 cases of BRVO. The study was conducted afterapproval of the Institution's Ethical Committee.

Sampling methods and sample collection- Assuming a mean change in BCVA from baseline of 5.0at month 6 and an SD of 10.6, a sample size of 18 patients was needed, and assuming a dropout rate of $30 \%$, approximately 21 patients needed to be recruited.
Detailed history was taken in patients attending retina out patients department (OPD). Visual acuity was measured using Snellen's chart. Anterior segment examination was done with slit lamp. Posterior segment examination was done with indirect ophthalmoscope and slit lamp biomicroscope with $+90 \mathrm{D}$ lens. Optical coherence tomography (OCT) was done to measure macular thickness. Patients having BRVO were included in the study. They were admitted and routine blood tests were done. Fasting blood sugar, post prandial blood sugar, $\mathrm{HbA} 1 \mathrm{C}$, serum urea, serum creatinine, lipid profile tests were checked. Thorough cardiovascular check-up was done in all patients. In the operation theatre under all aseptic conditions intravitreal injection of ranibizumab $0.5 \mathrm{mg}$ in $0.05 \mathrm{ml}$ provided free of cost by state government was given under topical anaesthesia in all patients. Visual acuity and macular thickness were examined at post-op day 1 . Follow up examinations were done at the end of 1 week, 1 month and 3 month.

Inclusion criteria- All patients diagnosed with BRVO. Exclusion criteria

1. Patients with BRVO unwilling to participate in the study.

2. Patients lost to follow up.

3. Patients with central retinal venous occlusion (CRVO).

4. Patients with diabetic macular oedema.

5. Patients with other retinal diseases.

Statistical methods: Clinical information, including systemic evaluation, ophthalmic examination, BCVA, and SD-OCT findings, was entered into the database sheets in Microsoft Excel. The statistical analysis employed SPSS software, version 16.0 (SPSS Inc., Chicago, Illinois, USA). Student's $t$-test was used to compare means among groups. $P$ value less than 0.05 was considered significant.

\section{Results}

21 patients with BRVO of age group 20 year to 79 year were included in the study. Mean age was $55.29 \pm 16.86$. Age distribution is shown in table no- 1 .

Table No-1: Age distribution of patients.

\begin{tabular}{|c|c|c|}
\hline Age group (yrs) & No. of patients & Percentage \\
\hline $20-40$ & 4 & $19.1 \%$ \\
\hline $41-60$ & 9 & $42.9 \%$ \\
\hline $61-80$ & 8 & $38 \%$ \\
\hline
\end{tabular}

$16(76.2 \%)$ patients were male and $5(23.8 \%)$ patients were female. Male: female ratio was 3.2:1. In 13 (72\%) cases left eye was involved and in 8 cases (38\%) right eye was involved. $7(33.3 \%)$ patients presented within 1 month of onset of 


\section{Original Research Article}

symptoms. 9 (42.9\%) patients presented after 1 month and before 6 months, whereas rest patients presented after 6 months. In most of the patients fasting blood sugar was within normal limit with mean FBS $=97.95 \pm 15.25$. Systolic blood pressure of $\geq 150$ was found in $9(42.9 \%)$ patients and diastolic blood pressure of $\geq 90$ was found in $17(81 \%)$ patients. $9(42.9 \%)$ patients had $\mathrm{HbA1C}>6.5 \%$ with mean $=6.42 \pm 0.013 \%$. In $9(42.9 \%)$ patients LDL level was $>100$ $\mathrm{mg} / \mathrm{dl}$. Table 2 shows the pre-operative and post-operative best corrected visual acuity (BCVA).

Table-2: Pre-operative and post-operative BCVA.

\begin{tabular}{|c|c|c|c|c|c|}
\hline BCVA & $\begin{array}{c}\text { Pre-operative } \\
\text { (No. of } \\
\text { patients) }\end{array}$ & $\begin{array}{c}\text { Post-operative } \\
\text { day 1 } \\
\text { (No. of } \\
\text { patients) }\end{array}$ & $\begin{array}{c}\text { Post-operative } \\
\text { 1 week } \\
\text { (No. of } \\
\text { patients) }\end{array}$ & $\begin{array}{c}\text { Post-operative } \\
\text { 1 month } \\
\text { (No. of } \\
\text { patients) }\end{array}$ & $\begin{array}{c}\text { Post-operative } \\
\text { 3 month } \\
\text { (No. of } \\
\text { patients) }\end{array}$ \\
\hline $6 / 6-6 / 12$ & $1(4.8 \%)$ & $4(19 \%)$ & $4(19 \%)$ & $6(28.6 \%)$ & $6(28.6 \%)$ \\
\hline $6 / 18-6 / 24$ & $4(19 \%)$ & $3(14.3 \%)$ & $6(28.6 \%)$ & $6(28.6 \%)$ & $6(28.6 \%)$ \\
\hline $6 / 36-6 / 60$ & $11(52.4 \%)$ & $11(52.4 \%)$ & $9(42.9 \%)$ & $8(38 \%)$ & $8(38 \%)$ \\
\hline$<6 / 60$ & $5(23.8 \%)$ & $3(14.3 \%)$ & $2(9.5 \%)$ & $1(4.8 \%)$ & $1(4.8 \%)$ \\
\hline
\end{tabular}

Most of the patients (52.4\%) presented with BCVA of 6/36- $6 / 60$ followed by $23.8 \%$ patients with BCVA of $<6 / 60$. 19 cases $(90.5 \%)$ showed improvement at 1 week post-operatively. At the end of 1 month 12 patients $(57.1 \%)$ showed good improvement of vision with $\mathrm{BCVA} \geq 6 / 24$ and 8 cases $(38.1 \%)$ retained BCVA of 6/36- 6/60. In 1 case (4.8\%) vision didn't improve. At the end of 3 month BCVA was not deteriorated in any patients. Graph-1 shows pre-operative and post-operative central macular thickness (CMT) (Figure-1)

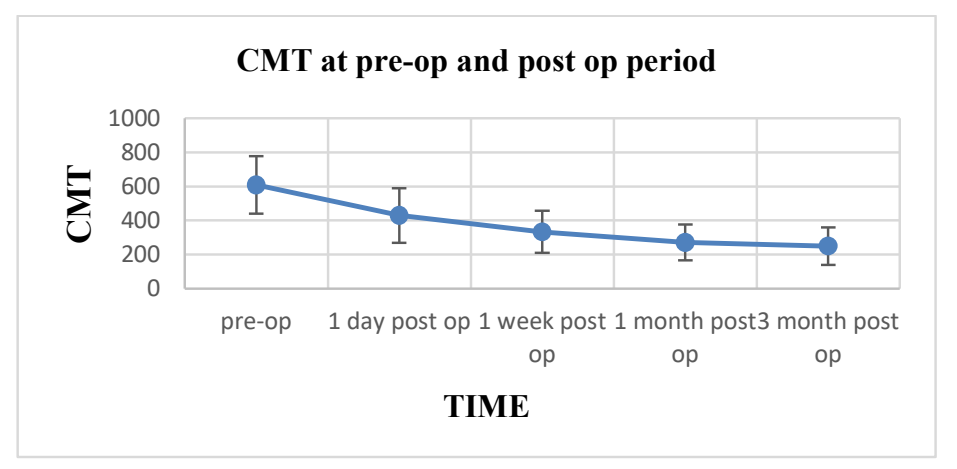

Figure-1:-Pre-operative and post-operative mean central macular thickness.

CMT at presentation was $609.05 \pm 170.04 \mu$. CMT at post-op day 1 was $429.62 \pm 160.31 \mu$, at 1 week $332.81 \pm 124.4 \mu$, at 1 month $270.14 \pm 105.12 \mu$ and at 3 month $249.71 \pm 110.28 \mu$. At post-operative day 1 CMT was significantly decreased $(p=0.0011)$. Gradual decrease in post-operative CMT was noted at each follow up visit. At the end of 3 month CMT became almost normal. Figure 1 shows the fundus photograph of a BRVO patient. Figure 2 shows the OCT images of retina at presentation and each follow up after giving intravitreal injection of ranibizumab (Figure-2,3)
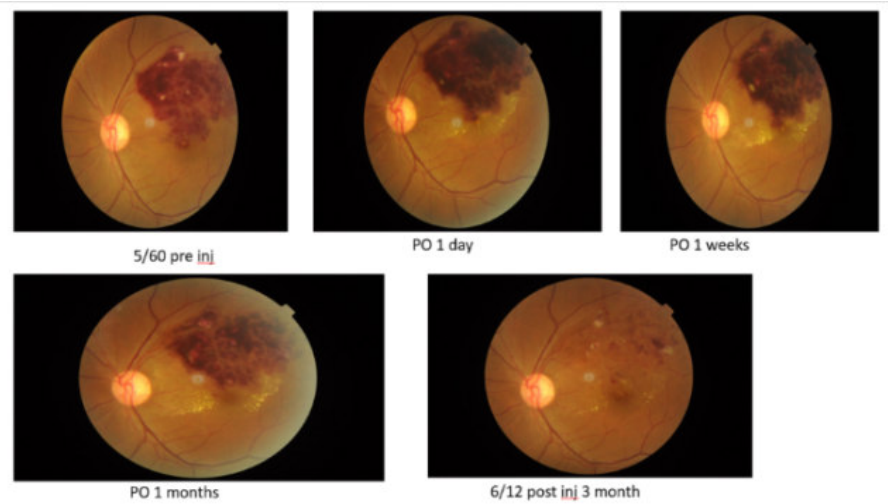

Figure-2: Fundus photograph of a patient with BRVO 


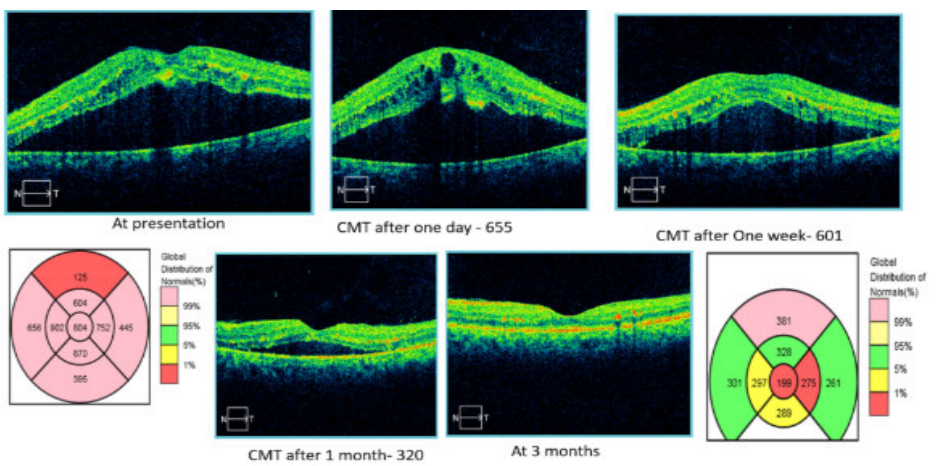

Figure-3: OCT image of retina at presentation and each follow up.

\section{Discussion}

Retinal vein occlusion (RVO) is the second most common retinal vascular disorder after diabetic retinopathy [5]. RVO is divided into central retinal vein occlusion (CRVO) and branch retinal vein occlusion (BRVO). Vascular compression during arteriovenous passages,degenerative changes in venous walls and hypercoagulability are the underlying pathophysiology of BRVO. Ranibizumab $0.5 \mathrm{mg}$ which is an anti-VEGF agent was approved in June 2010 for the treatment of ME due to BRVO and CRVO in the United States, based on the 6mo-results of two phase III, randomized, double-masked, 12mo, controlled study-BRAVO[6]. Requirement of multiple intravitreal anti-VEGF agent injections for initial treatment of ME after BRVO is not well figured out and they may increase the risk of systemic or ocular complications $[7,8]$.

21 patients with BRVO of age group 20 to 79 years were included in our study. A single $0.7 \mathrm{mg}$ dose of intravitreal injection of ranibizumab for treating patients with macular edema secondary to nonischemic CRVO or BRVO was associated with a significant and constant improvement in BCVA (0.15 at baseline compared with 0.71 after 6 months of follow-up) and with a marked reduction of CMT $(535.5 \mu \mathrm{m}$ at baseline compared with $281.3 \mu \mathrm{m}$ after 6 months of follow-up) in $90 \%$ of the patients which is nearly similar to that achieved by repeated injections with lower doses that was demonstrated in the study by Campochiaro et.al [9].

Campochiaro et al in a study of 397 BRVO patients found average age was 66 years and $53 \%$ were males. However in our study males comprises of $76.2 \%$. Campochiaro et al found the mean time from diagnosis of BRVO to screening was 3.5 months with duration $\leq 3$ months in $65 \%$ of patients. ${ }^{8}$ In our study $76.2 \%$ cases presented within 6 months of onset of symptoms. Mean study eye baseline BCVA was 6/18 and mean baseline CMT was $520.5 \mu$ in a study by Campochiaroet al [9].
In our study most of the patients (52.4\%) presented with BCVA of 6/36- $6 / 60$ followed by $23.8 \%$ patients with BCVA of $<6 / 60$ and mean pre-operative CMT of $609.05 \mu$. Campochiaro et al found after injection of ranibizumab patients gained an average of 7.5 letters 7 days after the first injection and improvement in BCVA letter score was greater for patients who were diagnosed with BRVO $<3$ months before study screening. 90.5\% showed improvement at 1 week post-operatively in our study and at the end of 3 month $57.1 \%$ had $\geq 6 / 24$ BCVA and $38.1 \%$ had BCVA of 6/36- $6 / 60$. Campochiaro et al found $64.9 \%$ patients obtained $\geq 6 / 12$ BCVA at 6 months and poor visual outcome of $<6 / 60$ was present in $0.8 \%$ patients [9].

In our study reduction in mean CMT at 7 day was $>270$ $\mu$ which is in accordance with Campochiaro et al who found at day 7 the mean reduction from baseline CMT was $>250 \mu$. Klein et al in a study found while adjusting for age, the prevalence of branch vein occlusion was associated with hypertension (odds ratio [OR] 5.42), diabetes mellitus (OR 2.43), pulse pressure (OR 1.24 for $10 \mathrm{~mm} \mathrm{Hg}$ ), ocular perfusion pressure (OR 2.09 for $10 \mathrm{~mm} \mathrm{Hg}$ ), arteriovenous nicking (OR 16.75), and focal arteriolar narrowing (OR 22.86).

While controlling for age, the incidence of branch vein occlusion was not associated with serum lipid levels [10]. In our study diastolic hypertension was found in $81 \%$ cases and elevated LDL level was found in $42.9 \%$ cases, however mean FBS and HbA1C wasfound to be within normal limits. In a recent study, Osaka et alstudied patients with ME secondary to CRVO. Twenty nine eyes of the patients were treated with $3+$ PRN regimens, while 20 eyes were treated $1+\mathrm{PRN}$ regimen [11]. They followed the patents for twelve month. At final visit, they reported that $1+\mathrm{PRN}$ regimen achieved visual outcomes similar to those of $3+\mathrm{PRN}$ regimen with fewer injections. 


\section{Original Research Article}

Ach et alreported that the initial CMT was a predictive factor for short and long-term responses to anti-VEGF treatment [12].

The multiple regression analyses showed that the pretreatment BCVA had the highest correlation with visual gain. Additional, the statistical analysis showed that the BCVA improvement at 12-month follow-up was better in the eyes with intact photoreceptor IS/OS layer. Similar to our conclusion, Shin et alalso found that integrity of IS/OS is significantly correlated with visual gain.In current literature, there is only one study comparing the single injections with 3 monthly injections of IVR in the treatment of ME due to BRVO [13].

Miwa et al confirmed that there is no significant difference between one and three monthly IVR injections as in our study [14]. During treatment with this high dose, there was neither serious ocular nor systemic drug-related adverse events (apart from paracentesis for lowering the intraocular pressure). These results were equivalent to that observed in multiple intravitreal injections of doses ranging from $0.3-0.5 \mathrm{mg}$ of ranibizumab or even $1.25 \mathrm{mg}$ intravitreal injection of bevacizumab for treating macular edema secondary to nonischemic CRVO or BRVO [15].

\section{Conclusion}

Ranibizumab is indicated for the treatment of visual impairment due to macular oedema secondary to BRVO or CRVO. Single intravitreal injection of ranibizumab $0.5 \mathrm{mg}$ causes significant increase in vision and significant reduction of central macular thickness in patients with branch retinal vein occlusion. For hemiretinal RVO, a treatment approach similar to that for BRVO is suggested.

When treating newly diagnosed RVO, physicians should be aware of common risk factors, to follow good clinical practice and refer patients to the appropriate specialist if necessary. Physicians should be vigilant for signs of rubeosis during follow-up of all RVO cases, particularly CRVO. The role of ranibizumab in the prevention and management of rubeosis is still unclear and requires further study.

\section{What this study add to existing knowledge}

1. Retinal vein occlusion (RVO) is a common cause of retinal vascular disease, resulting in potentially irreversible loss of vision despite the existence of several therapeutic options.
2. The humanised monoclonal antibody fragment ranibizumab binds to and inhibits vascular endothelial growth factor, a key driver of macular oedema in RVO.

3. In 2010, ranibizumab was approved in the USA for the treatment of macular oedema in RVO and, in 2011, ranibizumab was approved in the European Union for the treatment of visual impairment caused by macular oedema secondary to RVO in branch and central RVO.

4. Ranibizumab provides an additional therapeutic option for this complex disease: an option that was not fully considered during the preparation of current international guidelines

5. In our study, ranibizumab treatment was associated with significant improvements in BCVA, observed from day 7, with BCVA gains sustained over 12 months of treatment.

\section{Authors' Contributions}

1. Dr Ashwani Meherda: Conceived the original idea and preparation of the manuscript

2. Prof. Dr. Subhabrata Parida: Involved in manuscript preparation, drafting and critically revising the work

3. Dr Deepak Choudhury: Maintenance of data and follow up of patients

4. Dr Nikita Dash: Statistical analysis and collection of references

5. Mr Akbar MehfuzAlam: Data collection, drafting and critically revising the work

Funding: Nil, Conflict of interest: Nil

Permission from IRB: Yes

\section{References}

1. Hayreh SS, Zimmerman B, McCarthy MJ, et al. Systemic diseases associated with various types of retinal vein occlusion. Am J Ophthalmol. 2001 Jan;131 (1):61-77.

2. Hayreh SS. Classification of central retinal vein occlusion. Ophthalmology 1983; 90:458-474The eye disease case-control study group. Risk factors for branch retinal vein occlusion. American journal of ophthalmology. September 1993; 116(3): 286-96.

3. Brown BA, Marx JL, Ward TP, et al. Homocysteine: a risk factor for retinal venous occlusive disease. Ophthalmology. 2002 Feb;109(2):287-90.

4. Aiello LP, Avery RL, Arrigg PG, et al. Vascular endothelial growth factor in ocular fluid of patients with diabetic retinopathy and other retinal disorders. N Engl 
J.Med. 1994 Dec 1;331(22):1480-7.DOI:10.1056/ NEJ M199412013312203

5. Ozaki H, Hayashi H, Vinores SA, et al. Intravitreal sustained release of VEGF causes retinal neovascularization in rabbits and breakdown of the blood-retinal barrier in rabbits and primates. Exp Eye Res. 1997 Apr; 64 (4) :505-17. DOI:10.1006/exer. 1996. 0239

6. Ferrara N, Damico L, Shams N, et al. Development of ranibizumab, an anti-vascular endothelial growth factor antigen binding fragment, as therapy for neovascular age-related macular degeneration. Retina. 2006 Oct; 26 (8): 859-70. DOI: 10.1097/01.iae. 0000242842.14624.e7

7. Rayess N, Rahimy E, Shah CP, et al. Incidence and clinical features of post-injection endophthalmitis according to diagnosis. Br J Ophthalmol. 2016 Aug;100 (8) :1058-61. doi: 10.1136/bjophthalmol-2015-307707. Epub 2015 Nov 19.

8. Kida T, Tsujikawa A, Muraoka Y, Harion S, Osaka R, Murakami T, Ooto S, Suzuma K, Maroishita S, Fukumoto M, Suzuki H, Ikeda T. Cotton wool spots after anti-vascular endothelial growth factortherapy for macular edema associated with central retinal vein occlusion. Ophthalmologica. 2016;235(2):106-113.

9. Campochiaro PA, Heier JS, Feiner L, et al. Ranibizumab for macular edema following branch retinal vein occlusion: six-month primary end point results of a phase III study. Ophthalmology. 2010 Jun;117(6):1102-1112.e1. doi: 10.1016/j.ophtha. 2010 .02.021. Epub 2010 Apr 15 .
10. Klein R, Klein BE, Moss SE, et al. The epidemiology of retinal vein occlusion: the Beaver Dam Eye Study. Trans Am Ophthalmol Soc. 2000;98:133-41; discussion 141-3.

11. Osaka R, Muraoka Y, Miwa Y, et al. Anti-Vascular Endothelial Growth Factor Therapy for Macular Edema following Central Retinal Vein Occlusion: 1 Initial Injection versus 3 Monthly Injections. Ophthalmologica. 2018;239 (1):27-35. doi: 10.1159/ 000479049. Epub 2017 Sep 26.

12. Ach $\mathrm{T}^{1}$, Hoeh $\mathrm{AE}$, Schaal KB, et al. Predictive factors for changes in macular edema in intravitreal bevacizumab therapy of retinal vein occlusion. Graefes Arch Clin Exp Ophthalmol. 2010 Feb;248(2):155-9. doi: 10.1007/s00417-009-1167-6. Epub 2009 Sep 9.

13. Shin HJ, Chung H, Kim HC. Association between integrity of foveal photoreceptor layer and visual outcome in retinal vein occlusion. Acta Ophthalmol. 2011 Feb;89 (1):e35-40. doi: 10.1111/j. 17553768.2010.02063.x.Epub 2010 Dec 14.

14. Miwa Y, Muraoka Y, Osaka R, Ooto S, Murakami T, Suzuma K, Takahashi A, Iida Y, Yoshimura N, Tsujikawa A. Ranıbızumab for macular edema after branch retinal vein occlusion one initial injection versus three monthly injections. Retina. 2017;37(4):702-709.

15. Prager F, Michels S, Kriechbaum K, et al. Intravitreal bevacizumab (Avastin) for macular oedema secondary to retinal vein occlusion: 12-month results of a prospective clinical trial. $\mathrm{Br} \mathrm{J}$ Ophthalmol. 2009 Apr;93(4):452-6. doi: 10.1136/bjo.2008.141085. Epub 2008 Dec 15.

\section{How to cite this article?}

Meherda A., Parida S., Choudhury D., Dash N., MehfuzAlam A. Outcome following single intravitreal injection of ranibizumab in branch retinal vein occlusion patients: a single centre experience. Trop J Ophthalmol Otolaryngol. 2019;4(2): 65-70. doi: 10.17511/jooo.2019.i02.01 